\title{
Small Strain Stiffness of Artificially Cemented Soft Clay: Modelling the Effect of Structure Degradation
}

\author{
Qasim $\mathrm{Khan}^{1}$, Yannick $\mathrm{Ng}^{1}$, and Taeseo $\mathrm{Ku}^{1 *}$ \\ ${ }^{1}$ National University of Singapore, Department of Civil \& Environmental Engineering, Singapore
}

\begin{abstract}
This paper presents a study on the evolution of small strain stiffness $\left(G_{\max }\right)$ along vertical and horizontal directions for lightly cemented clay. Soft clays have historically been a subject for studying the evolution of stiffness anisotropy under varying loading conditions. These studies have focused on stress history (overconsolidation) effects as well. However, for lightly cemented clays, such studies are limited and their main scope has primarily been on the evolution of vertically aligned stiffness $\left(G_{V H}\right)$ at varying effective confining stresses. This study investigates the effect of isotropic loading on uncemented and lightly cemented kaolin clay. Kaolin clay mixed with $10 \%$ cement is used in this study. Stiffness measurements have been conducted using bender elements for obtaining $G_{V H}$ and $G_{H H}$ hence resulting in the measurement of vertical and horizontal stiffness values respectively. By comparing the behaviour of both samples, the influence of bonding and fabric due to cementation on the evolution of stiffness and anisotropy is studied. In order to characterize the behavior of structure in cemented soil with confining stress, a modelling equation is applied for the cemented sample to predict the variation of $G_{\max }$ before and after yielding.
\end{abstract}

\section{Introduction}

Mixing soft clays with cement is a common practice for soil improvement as it results in imparting higher strength and reduced compressibility. Therefore, various studies investigating the influence of the structure due to cementation on small strain stiffness have been done [15]. A combination of bonding and fabric forms the basis for defining structure in clayey soils $[6,7]$. Cement mixing allows the formation of cementation bonds within the soil fabric hence introducing structure within the clay. The structure (due to cementation) produces higher small strain shear stiffness ' $G_{\max }$ ' for clayey soils in comparison to their corresponding reconstituted forms at the same mean effective stress $[2,8]$. In general, $G_{\max }$ is found to be a function of mean effective stress $p^{\prime}$, stress history, and void ratio for most soil types $[9,10$, 11]. Moreover, anisotropy in soils is generally characterised by utilizing directional values of $G_{\max }$ (i.e., $G_{V H}$ and $G_{H H}$ ). Stress induced anisotropy is widely studied by measuring $G_{V H}$ and $G_{H H}$ along the vertical and horizontal directions, respectively [12-15]. However, for cemented soils, the effect of the mean effective stress on the small strain stiffness is found to be less significant at confining stresses below the isotropic or vertical yield stress. In this region, cementation controls the value of $G_{\max }$ as the presence of structure within the soil limits the change in void ratio $[2,3]$. However, beyond the yield point, the soil transits into a stress-controlled regime. Cafaro \& Cotecchia [16] and Cuccovillo \& Coop [17] reported $G_{\max }$ to reduce after yielding at higher confining stresses. On the contrary, several other studies showed it to increase and stay above $G_{\max }$ values for corresponding reconstituted clays by applying either isotropic or one dimensional oedometer compression tests. $[1,3,4]$.

In this paper, the variation of $G_{V H}$ under isotropic compression loading for kaolin clay mixed with $10 \%$ cement cured for 28 days, is presented. The resulting strength using $10 \%$ cement content falls within a relatively inactive zone of cement treatment applications [18]. Within an inactive zone, the rate of strength gain using cement mixing is significantly lower. As strength and stiffness are well correlated with each other for cement treated clays, the stiffness for the chosen mix ratio is expected to be proportionately low as well. Therefore, it is termed to be a lightly cemented mix ratio for the purpose of this study. Furthermore, by using measurements of $G_{V H}$ and $G_{H H}$, the presence of anisotropy is also investigated. In addition, pure remolded kaolin clay is also subjected to isotropic compression with stiffness measurements as well. Consequently, a comparison between both types of specimens enables the presence of stiffness anisotropy due to cementation to be investigated. The specimens were subjected to a loading and unloading. A model that predicts the variation of $G_{\max }$ during the entire loading regime is proposed for cemented soil. The proposed model is an extension of Trhlíková et al. [1] to predict $G_{V H}$ for all loading and unloading steps using cemented specimens.

\footnotetext{
* Corresponding author: ceekt@nus.edu.sg
} 


\section{Materials and Experimental Setup}

Kaolin clay (Liquid Limit $=80 \%$ and Plasticity Index $=42 \%$ ) was utilized in this experiment to prepare cement-mixed clay specimens. The water content based on the combined mass of soil and cement solids, was taken as $77 \%$. The samples were mixed in a Hobart mixer for 10 minutes to ensure uniform mixing. Similarly, remolded kaolin is prepared by mixing dry kaolin with $120 \%$ water. A soil-cement slurry was made by mixing kaolin powder with distilled water and Ordinary Portland Cement. Based on the mass of soil solids, the amount of cement was taken to be $10 \%$. After mixing, the samples were cast in PVC moulds (internal diameter $=70 \mathrm{~mm}$ and height $=140 \mathrm{~mm}$ ) and cured in water at room temperature, $23 \pm 1{ }^{\circ} \mathrm{C}$. The remolded clay sample was prepared using a similar mixing procedure. After the mixing was completed, the remolded clay mixture was transferred into a consolidometer (internal diameter $=70 \mathrm{~mm}$ ) and consolidated under a vertical stress of $75 \mathrm{kPa}$. When the prescribed 28-day curing (or consolidation) period was complete, the sample was trimmed and then placed onto the triaxial base pedestal.

For the cemented specimen, the saturation process was completed using a back pressure of $550 \mathrm{kPa}$ for the specimens ( $\mathrm{B}$ value $\geq 0.9$ ). However, the back pressure for remolded clay was $350 \mathrm{kPa}$ ( $\mathrm{B}$ value $\geq 0.95$ ). Cementmixed specimens are continuously curing that can cause strength gain even during testing. Therefore, higher back pressure ensures faster saturation for such stiff samples [19]. The rate of isotropic compression was $0.15 \mathrm{kPa} /$ min, which is slow enough to ensure the dissipation of excess pore pressure during the entire testing period.

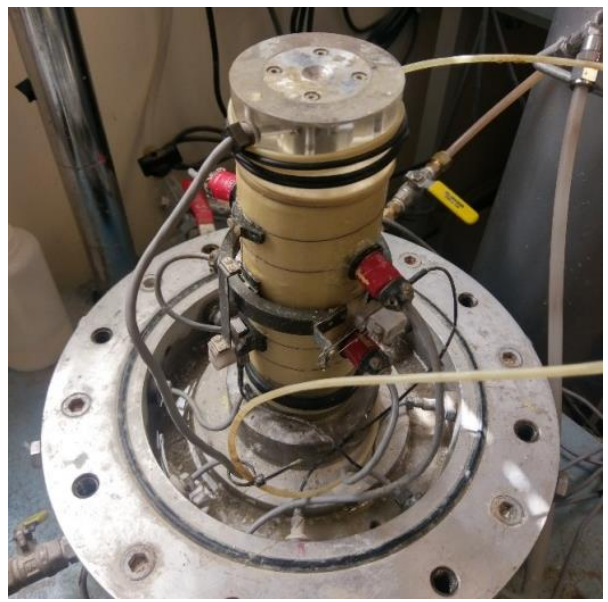

Figure 1: Setup of bender elements and Hall effect transducers.

The test setup is shown in Figure 1. It involves the use of multiple pairs of bender elements for wave travel time measurements. A single pair of vertical bender elements (embedded in base pedestal and top cap) measures the $V_{S V H}$ mode while the horizontal pair measures $V_{S H H}$. The bender element tip-to-tip distance was used as the travel distance for calculating shear wave velocity [20]. In Figure 2, the isotropic compression lines for both the specimens are presented. The points labelled on the isotropic compression curve correspond to stresses at which readings from bender elements were taken to measure $V_{S V H}$ and $V_{s H H}$. The bender elements readings were taken at various stress intervals with the aim of covering the pre-yield, postyield, and unloading regions.

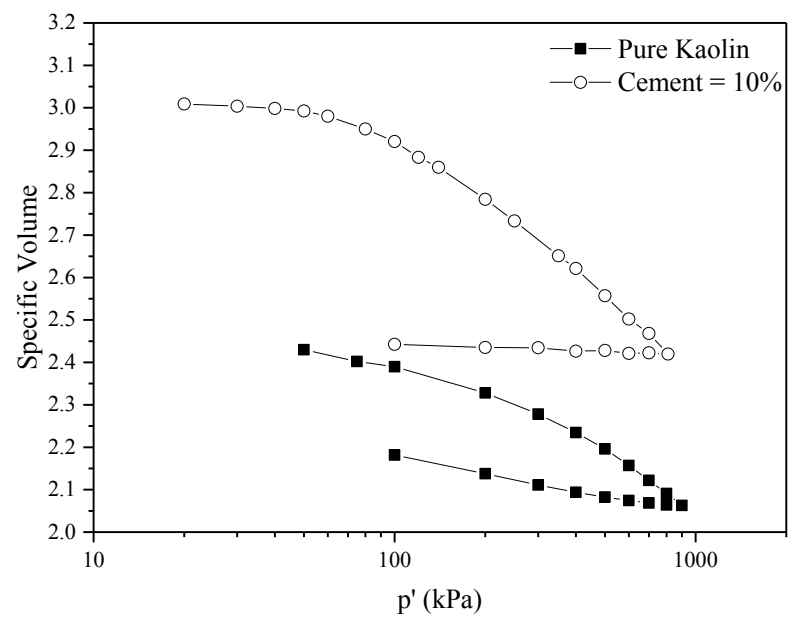

Figure 2: Isotropic compression curves for uncemented and cement-mixed clay specimens.

By utilizing the travel time $(\Delta t)$ and the tip-to-tip distance, the shear wave velocity $V_{s}$ can be calculated. The values of $G_{\max }$ are then calculated using the relation $G_{\max }=\rho V_{s}^{2}$, where ' $\rho$ ' is the bulk density of soil in $\mathrm{kg} / \mathrm{m}^{3}$. The signals with arrival times are summarised in Figure 3 for each curing time. The first arrival (zero crossing) method is applied to measure $\Delta t$ throughout the test. The signals for all modes were collected at input frequencies between 5 and $50 \mathrm{kHz}$ to reduce the near field effects. This is to achieve the minimum travel distance to wavelength $\left(L_{t t} / \lambda\right)$ ratio of 2 or more recommended by several previous studies $[20,21,22,23]$.

\section{Methodology}

As mentioned previously, the variation of $G_{\max }$ of cemented soil in the pre-yield region is predominantly dependent on the state of soil structure. Larger confining stresses cause the soil to yield and degrade its structure. Thereafter, $G_{\max }$ becomes primarily dependent on the current stress state. For reconstituted clays, $G_{\max }$ is expressed in terms of the mean effective stress and stress history using Equation 1 based on the relationship proposed by [24]:

$$
\frac{G_{\max }}{p_{r}}=A\left(\frac{p^{\prime}}{p_{r}}\right)^{1}\left(\frac{p_{p}^{\prime}}{p^{\prime}}\right)^{m}
$$

where $p_{r}$ is the reference pressure $(1 \mathrm{kPa}), p^{\prime}$ is the mean effective stress, and $p_{p}^{\prime}$ represents the yield stress. $A, l$, and $m$ are dimensionless soil parameters. The parameter ' $A$ ' represents the $G_{\max }$ value of reconstituted normally consolidated clay at $p^{\prime}=p_{r}$. In addition, ' $l$ ' and ' $m$ ' relate the effect of mean effective stress and overconsolidation 
ratio on $G_{\max }$ respectively. In order to consider the effects of structure, Equation 1 was further modified into Equation 2 by Trhlíková et al. [1], based on the framework proposed by Cafaro \& Cotecchia [16] and Cotecchia \& Chandler [25]:

$$
\frac{G_{\max }}{p_{r}}=A\left(\frac{p^{\prime}}{p_{r}}\right)^{1}\left(\frac{p_{e}^{\prime}}{p^{\prime}}\right)^{m}\left(\frac{s}{s_{f}}\right)^{n}
$$

where $p_{e}^{\prime}$ is the Hvorslev equivalent pressure. By adding the third term (stress sensitivity ratio), Equation 2 incorporates the contrast between pre-yield and postyield behaviour for cemented clay hence improving the modelling of $G_{\max }$. The sensitivity ratio quantifies the difference between the specific volumes of cemented and remolded states of soil due to the presence of structure. It is calculated using $s=p^{\prime} e_{e} / p_{e}^{\prime}$ where $p_{e}^{\prime}{ }^{*}$ is the Hvorslev equivalent stress for remolded soil. The value of $s$ remains constant in the pre-yield region and reduces during post-yielding towards $s_{f}$ (the stable state of soil) hence accounting for structural degradation with increasing confining stresses (i.e., $s=s_{f}$ in reconstituted soil). The second term, characterizing stress history effect in Equation 1, is modified to apparent overconsolidation ratio $\left(p_{e}^{\prime} / p^{\prime}\right)$ brought about by cementation [1]. This ratio accounts for the higher $G_{\max }$ due to cementation at the pre-yield state compared with the reconstituted clay at corresponding $p^{\prime}$. After yielding, the cementation effect disappears and $p_{e}^{\prime}=p^{\prime}$. The term $p_{e}^{\prime}$ is calculated using Equation 3, which represents:

$$
\mathrm{p}_{\mathrm{e}}{ }^{\prime}=\exp \left(\frac{\mathrm{N}-\ln (1+\mathrm{e})}{\lambda^{*}}\right)
$$

where $\lambda^{*}$ is the slope of intrinsic compression line (ICL), $N$ is the value for $\ln (1+e)$ at $p^{\prime}=p_{r}^{\prime}=1 \mathrm{kPa}$ and $e$ is the void ratio. For reconstituted clay, $\lambda^{*}$ and $N$ are constant. The term $N$ embodies the degradation in sensitivity (and structure) as the value reduces. Even though the improvement from Equation 2 is crucial in accounting for structure to model $G_{\max }$, further modification to model the unloading region is also necessary. This is because the existing framework can only predict up to the loading phase and does not provide a prediction within the unloading region.

The current study involves both loading and unloading regions for investigating the variation of $G_{\max }$. Therefore, Equation 2 is applied to model the variation of $G_{\max }$ for the unloading region as well. Consequently, a unified relationship for modelling $G_{\max }$ in pre-yield, post-yield, and unloading regions is applied on the experimental data collected for the cement-mixed kaolin at 28 days curing. The stiffness along the vertical and horizontal directions $\left(G_{V H}\right.$ and $\left.G_{H H}\right)$ are modelled using the above framework. In case the stiffness dependency is anisotropic for the specimen, it would be reflected by the modelling parameters that govern the dependency of $G_{\max }$ in Equation 3.
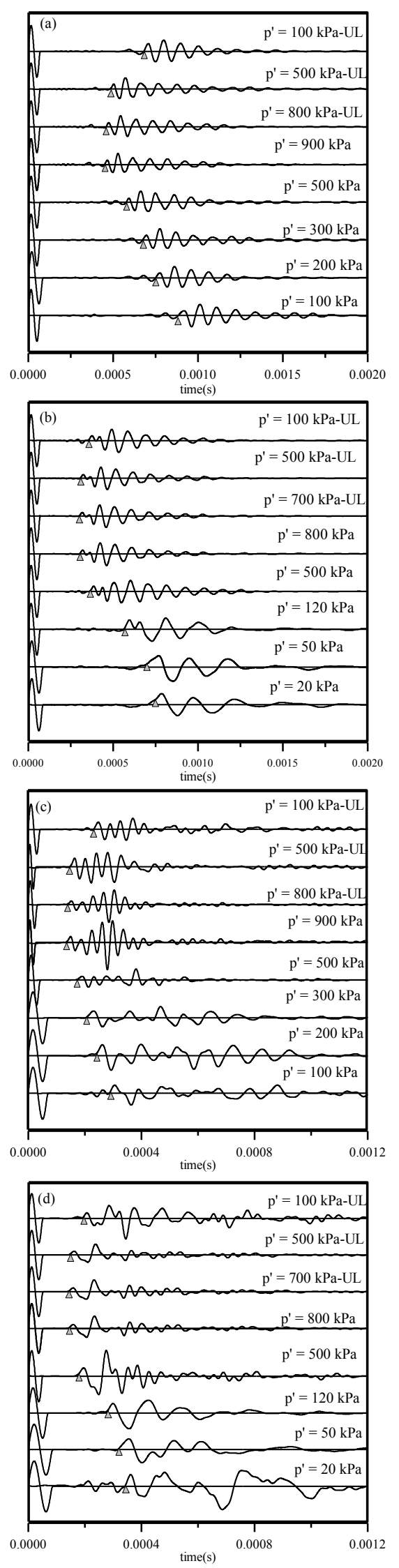

Figure 3: $V_{s}$ signals from a) Pure Kaolin-VH, b) Cemented Kaolin-VH, c) Pure Kaolin $-\mathrm{HH}$, and d) Cemented Kaolin - HH.

Note: UL means Unloading 


\section{Results and Discussion}

As shown in Figure 2, the cemented soil has a higher specific volume than the uncemented kaolin clay. It is observed that the change in specific volume throughout the compression phase is larger in the cemented clay. Similar results were obtained by Xiao [26] for cement treated Singapore marine clay. The yield point for the cemented specimen was obtained using the definition given by Rotta et al. [27] who identified the point of deviation from a linear behaviour to be the yield point on a linear scale.

The variation of $G_{V H}$ and $G_{H H}$ with confining stresses for both the cemented and uncemented is illustrated in Figure 4. Interestingly, the difference between the shear moduli in each mode (vertical and horizontal) for the cemented and uncemented specimens is not very significant. Due to cementation, it is generally expected to have a fairly high rate of increase in stiffness for clays. However, as mentioned previously, the cement content utilized for this study falls within a relatively inactive zone for exhibiting strength gain. Therefore, it is expected that specimens with low cement contents would not possess significantly higher stiffness than remolded specimens. However, the bonding and fabric formed due to cementation does control the $G_{\max }$ in preyield zone. The cemented sample exhibits a typical behaviour of low stress dependency of $G_{\max }$ in pre-yield zone followed by a substantial increase in $G_{\max }$ at higher stresses in the post yield zone. In contrast, the pure clay seems to exhibit complete stress dependency for both the stiffness modes. Moreover, the horizontal stiffness $\left(G_{H H}\right)$ is larger than the vertical stiffness $\left(G_{V H}\right)$. Similar results for kaolin clay were reported by Jovičić et al. [28] and Kuwano et al. [29]. Based on the exponents of the power fitting functions for both modes in Figure 4(a), the horizontal stiffness seems more stress dependent than the vertical stiffness due to its higher exponent. Even for unloading, a similar stress dependency of the horizontal mode is observed.

Interestingly, for the cemented soil, the post-yield loading zone also exhibits a similar trend of stress dependency to the remolded state for each mode of stiffness. However, both $G_{V H}$ and $G_{H H}$ modes seem to exhibit far less anisotropy (virtually equal) due to the uniform fabric formed as a result of cementation. The exponents for both $G_{H H}$ and $G_{V H}$ are slightly higher than the remolded specimen as shown in Figure 4(b). A possible reason for the higher values could be the increased brittle behaviour of the cemented specimen due to the presence of cementitious bonds. However, when the specimens are unloaded to effective stresses far below the second yield point $(800 \mathrm{kPa})$, the stress dependency of the vertical mode is greatly reduced and the exponent decreases to 0.11. Even the horizontal stiffness does illustrate less stress dependency than the remolded state for unloading but it is still substantially higher than the vertical stiffness. In Figure 3, the signals indicate that the arrival times start to increase as the specimen is unloaded to confining stresses as low as 100 $\mathrm{kPa}$ for both specimens. Therefore, the parameters that control stress and overconsolidation effects must be adjusted to capture this behaviour. The unloading behaviour of the cemented specimens at effective stresses below the second yield point is possibly anisotropic in nature similar to the behaviour observed for the pure clay. Consequently, the above experimental results highlight the importance of identifying the vertical and horizontal stiffness for investigating the stiffness behaviour of cemented soil.

Equation 2 is applied to the $G_{\max }$ data for both the modes of shear stiffness. Using the fitting parameters indicated in Figure 5, the modelled behaviour closely follows the experimental data. The fitting parameters for stress dependency and sensitivity are the same for both modes.
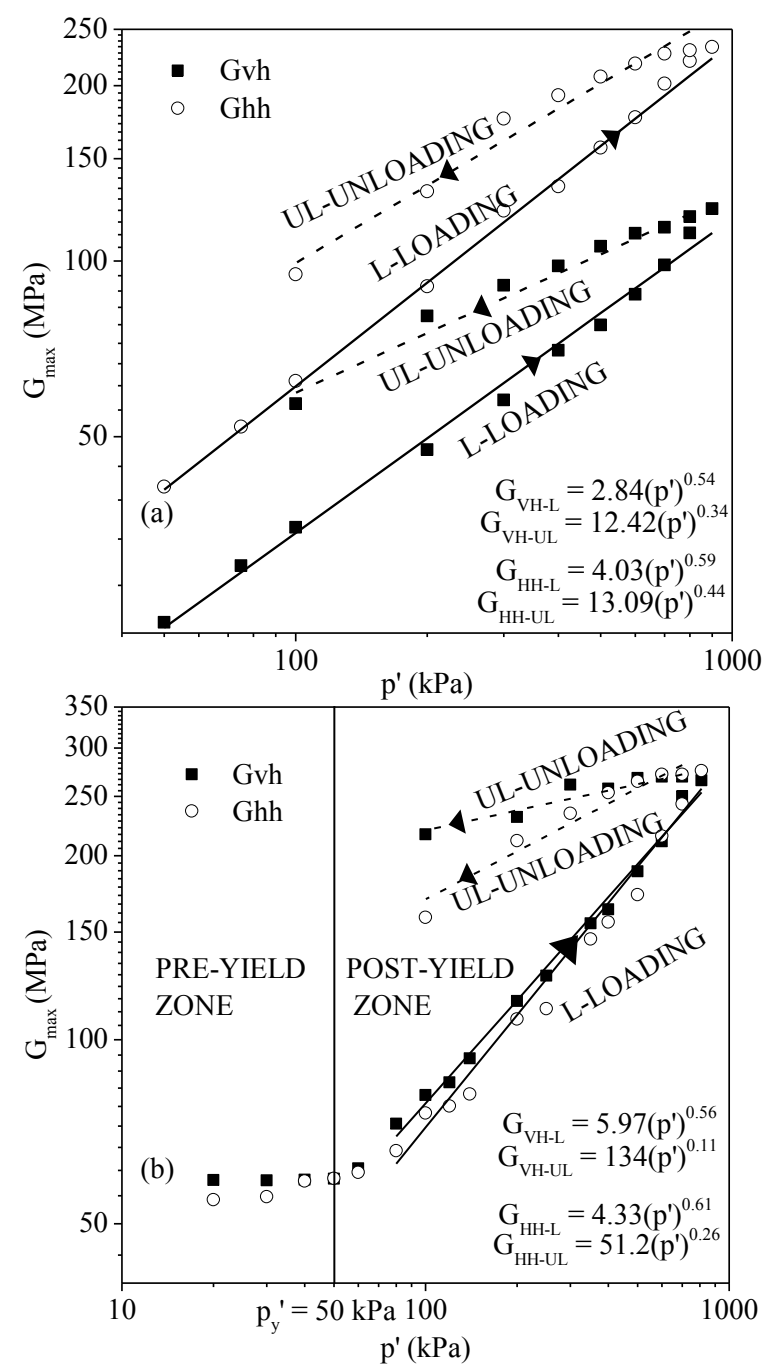

Figure 4: Stress dependent behavior of $G_{V H}$ and $G_{H H}$ observed from a) Pure Kaolin and b) Cemented Kaolin.

The values of $\lambda^{*}$ and $N$ are based on the intrinsic compression line adapted for typical kaolin clay obtained from the isotropic compression test of remolded state. It can be observed that Equation 2 closely predicts the $G_{\max }$ up to the yield point $\left(p_{y}{ }^{\prime}=50 \mathrm{kPa}\right)$ but indicates a slight upward trajectory rather than constant $G_{\max }$ in the preyield zone. A feature of the proposed equation in contrast to the previous ones is that it can closely predict the unloading behaviour as well. Therefore, the value of exponent ' $m$ ' that controls the influence of over- 
consolidation is reduced for the $G_{H H}$ mode in order to capture the sharper reduction in horizontal stiffness during unloading.
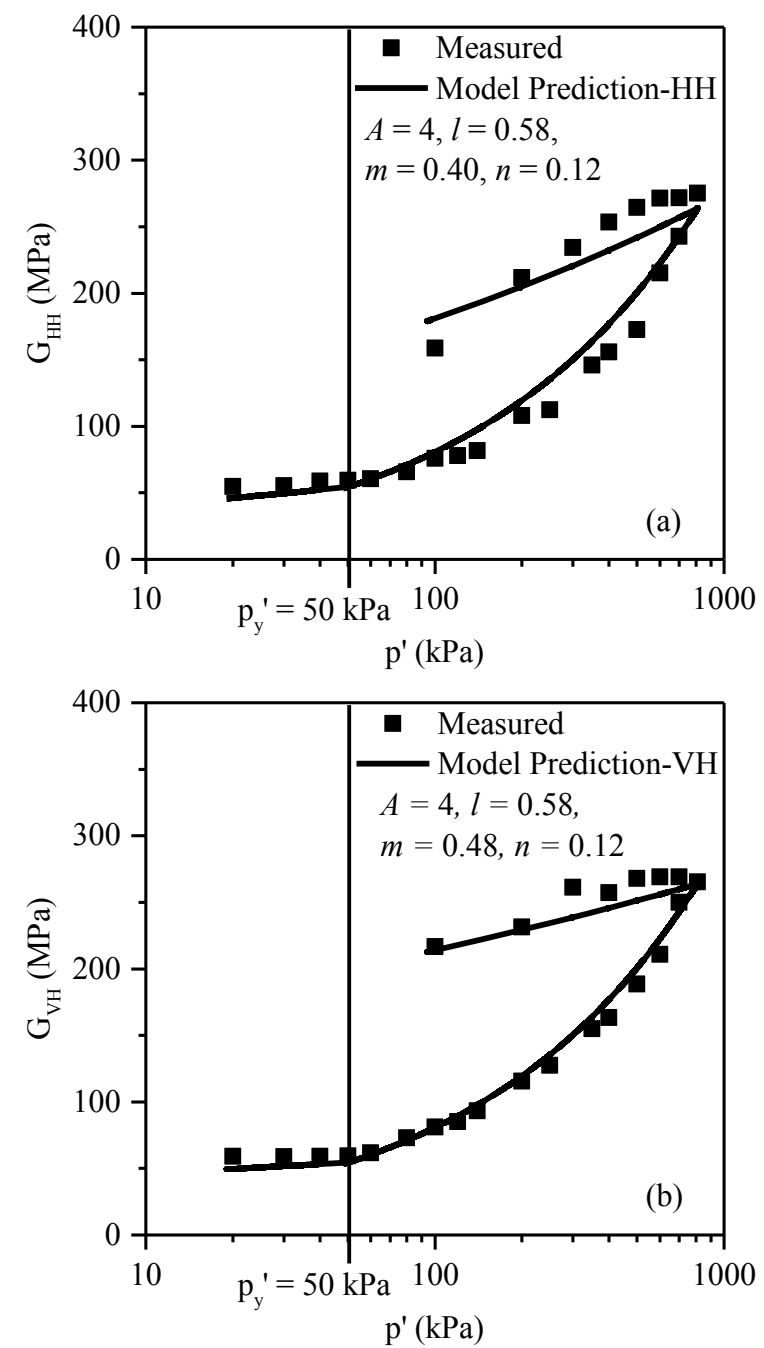

Figure 5: $G_{\max }-p^{\prime}$ plots for cemented kaolin samples with model ; a) $G_{H H}$, b) $G_{V H}$.

\section{Conclusions}

Isotropic compression tests were conducted on pure and cement-mixed kaolin clay to study the variation of $G_{V H}$ and $G_{H H}$ with confining stress. As the pre-yield zone in cemented soil is controlled by structure due to cementation bonds, the change in $G_{\max }$ was observed to be minimal in this region. However, at higher stresses beyond yielding, cementation bonds breakage was initiated and the structure degraded, resulting in stress dependent behavior of $G_{\max }$. For the pure kaolin, $G_{H H}$ mode was much higher than $G_{V H}$ mode which is similar to the behaviour reported previously. Due to a largely uniform structure as a result of cementation, $G_{H H}$ was found to be similar $G_{V H}$ for the cemented specimen.

In both the specimens, the stress dependency of each stiffness mode was similar during the loading and unloading stages. In the loading stage, the exponents that define stress dependency for $G_{V H}$ and $G_{H H}$ were quite close to each other for both pure and cemented kaolin. Interestingly, during unloading, the $G_{H H}$ mode was more stress dependent than $G_{V H}$ in both specimens. Due to cementation bonding, this stress dependency during unloading reduced drastically for $G_{V H}$ but $G_{H H}$ of the cemented specimen still exhibited considerably higher stress dependency than $G_{V H}$. An equation to model the behavior of $G_{\max }$ is also evaluated to capture the unloading-reloading region of cemented soils. Even though this study is limited to a single cement content with a single curing time, it showed a single equation can be used to reasonably predict the variation of $G_{\max }$ from pre-yield to post-yield as well as unloading. Further model validations are nonetheless being carried out to investigate a wider range of cement contents and curing days.

This research was supported by the Singapore Ministry of Education (MOE), Award No. R-302-000-194-114.

\section{References}

1. J. Trhlíková, D. Masin, and J. Bohác, Géotechnique 62 (10), 943 (2012)

2. V. Jovičić, M. Coop, and B. Simpson, Can. Geotech J. 43 (4), 341 (2006)

3. Hird, C. and C.-M. Chan, Geotech Test J, 31(2), 166 (2007)

4. T. S. Yun and J. C. Santamarina, J Geotech Geoenviron, 131 (3), 350 (2005)

5. Vinoth, G., Moon, S.W., Moon, J. and Ku, T.* (2018). Soils Found, 58 (5), 1200 (2018)

6. Burland, J., Géotechnique, 40(3), 329 (1990)

7. Leroueil, S. and P. Vaughan, Géotechnique, 40(3), 467 (1990)

8. A. J. Puppala, R. Kadam, R. S. Madhyannapu, and L. R. Hoyos, J Geotech Geoenviron, 132 (3), 322 (2006)

9. B. Hardin and J. Richart, FE, Geotech Test J Geotech Geoenviron, ASCE 89 (SM1, Proc. Paper 3407), 33 (1963)

10. F. Richart, J. Hall, and R. Woods, (Englewood Cliffs, NJ: Prentice-Hall, 1970)

11. Ku, T.*, and Mayne, P.W. (2015). Geomechanics and Geoengineering, 10 (1), (2015)

12. G. Mitaritonna, A. Amorosi, and F. Cotecchia, RIG, 44 (1), 50 (2010)

13. D. S. Pennington, D. F. Nash, and M. L. Lings, Geotech Test J, 24 (2), 133 (2001)

14. Ku, T.*, and Mayne, P.W. (2013), J APPL GEOPHYS, 94, 15 (2013)

15. Ku, T.*, and Mayne, P.W. (2014). Proceedings of the Institution of Civil Engineers (ICE) Geotechnical Engineering, 167 (5), 476 (2014)

16. F. Cafaro and F. Cotecchia, Géotechnique 51 (5), 441 (2001)

17. T. Cuccovillo and M. Coop, Pre-failure deformation behaviour of geomaterials, 105 (1998)

18. Uddin, K. PhD Thesis. Asian Institute of Technology, Bangkok, Thailand (1994). 
19. H. Xiao and F. Lee, Proceedings of World Academy of Science, Engineering and Technology (PWASET) 33, 2070 (2008)

20. E. C. Leong, S. H. Yeo, and H. Rahardjo, Geotech Test J, 28 (5), 488 (2005)

21. Sanchez-Salinero, I., et al., Report GR 86-15, University of Texas, Austin, USA. (1986)

22. Khan, Q., Subramanian, S., Wong, D.Y.C., and $\mathrm{Ku}, \mathrm{T}$., Can. Geotech J., (2018).

23. Khan, Q., Moon S.W. and Ku, T., Geotech Test J., (2019).

24. Viggiani and J. Atkinson, Geotechnique 45 (2), 249 (1995)

25. Cotecchia, F. and R. Chandler, Géotechnique, 50 (4), 431 (2000).

26. Xiao, H. PhD Thesis. National University of Singapore, Singapore. (2009)

27. G. Rotta, N. Consoli, P. Prietto, M. Coop, and J. Graham, Géotechnique 53 (5), 493 (2003).

28. Jovičić, V. and M. Coop, Geotech Test J, 21 (1), 3 (1998).

29. R. Kuwano and R. Jardine, Pre-failure deformation behaviour of geomaterials, ICE London Thomas Telford Ltd, 391 (1998). 